\section{Prevention of melanoma in Torbay}

EdrToR,-In 1990 I visited Sydney Melanoma Clinic as a surgeon interested in the treatment of malignant melanoma. What struck me most about my visit to Australia was the high level of public awareness about melanoma and the way that the message about skin care in the sun was communicated to the public. On my return to Britain I tried to persuade local councils to offer an information service. It is now a statutory requirement that beach users are informed about the bacteriological quality of sea water, and I wanted to establish information posts to tell the public about the dangers of overexposure to the sun.

My requests were almost universally dismissed. At least one resort pointed out that it would not do anything that might scare tourists away. By 1992 it became obvious that if anything was to be done I would have to to it myself.

Consequently, for a week in August last year the staff of the plastic surgery unit in Plymouth-in cooperation with the local health promotion team, Clinique Education, and Torbay council-undertook a pilot project. The aim was to show that an information stand was needed, and to assess the public's reaction to the provision of medical expertise on a beach.

Members of the team approached over 17000 beach users as they passed or neared the stand we had set up. Only 248 were uninterested in or hostile to the approach; well over $80 \%$ welcomed us. In addition, two previously unsuspected melanomas and 15 non-melanoma skin lesions were found and treated rapidly.

The pilot project thus proved successful. Local interest in Torbay means that a similar project will take place this year. We continue to press for further commitment from local councils in this area, where many people spend a lot of time in the sun. We believe that a coordinated programme is needed and have sent our findings to the Department of Health, but we have had no response.

JUDY EVANS

Subregional Plastic Surgery and Burns Unit, Derriford Hospital,

Plymouth PL6 8DH

\section{The dangers of boxing}

\section{Damage not confined to the brain}

EDrToR,-I join with the BMA in condemning the most vicious sport of boxing. ${ }^{1}$ I am not qualified to comment on the neurological damage that results from boxing, but I can comment on the damage inflicted on the nose.

Damage to the nose in a young person, before the nose has developed fully, is likely to interfere with its normal development and cause persistent nasal obstruction. The delicate nasal bones may be fractured and the cartilaginous septum broken into several pieces. Operations to restore an adequate nasal airway are rendered difficult by scarring that results from the damage to the septum. It is difficult to produce a satisfactory clean airway in a boxer's nose.

Before undertaking an operation to reconstruct a boxer's nose that has been badly damaged by punching I have always insisted that the patient

\section{Advice to authors}

Priority will be given to letters that are less than 400 words long and are typed with double spacing. All authors should sign the letter. Please enclose a stamped addressed envelope for acknowledgment.

stops boxing. Unfortunately, doctors who are employed by the British Boxing Board of Control do not recognise the difficulties. Their chief medical officer has told me that boxers are examined comprehensively at the end of each contest by the ringside physician. I do not know, however, whether the ringside doctors are trained in examining the nose or whether they can recognise a damaged nasal septum.

J SIEGLER

Liverpool L1 9EH

1 Dillner L. Boxing should be counted out, says BMA report. $B M \mathcal{Y}$ 1993;306:1561-2. (12 June.)

\section{Criminalisation would make it worse}

EdrTor,-Luisa Dillner's comments on the BMA's recent report, The Boxing Debate, deserve some comment in relation to the benefits and possible disbenefits of a ban on boxing. ${ }^{1}$ The governing bodies-the British Amateur Boxing Association and the British Boxing Board of Control, for amateur and professional boxers respectivelyacknowledge that boxing is a sport which carries more hazards to health than most other sports. It is, however, these bodies that make the sport as "safe" as possible by ensuring that boxers have regular medical examinations. Although Drew et al found that there were neuropsychological deficits consistent with the severe punch drunk syndrome in boxers who had fought under improved safety regulations, ${ }^{2}$ what would happen if boxing was banned and the control presently exerted by the regulatory bodies ceased to exist?

At least, at present, boxers have an opportunity to be examined regularly. If boxing was banned it would be naive to think that all boxers would stop boxing. Is it likely that the British Amateur Boxing Association's 35000 members would stop? More realistic is the possibility that these boxers would drift into the already well established underground boxing scene. The report suggests that this has not happened in Iceland, Sweden, and Norway, but this is open to debate. Britain, Italy, the United States, and some other countries have a much stronger culture of boxing than Norway and Iceland. Sweden, which the BMA's report includes as a country that has banned boxing, allows only amateur boxing. Professional boxers from Sweden tend to train in Denmark, or elsewhere, under the host country's licence.

The prevalent and also successful philosophy of minimisation of harm in other fields should be considered more seriously, at least in relation to amateur boxing. The prohibition of alcohol sales during the $1920 \mathrm{~s}$ in the United States showed what effect a "banning legislation" may have on the particular activity to be controlled. A harm reduction approach accepts that people will carry on with an activity even if it is banned and attempts to limit the harm caused by it. This is, in fact, what is done by the regulatory bodies, and if our profes- sion does not think about minimising harm we may go back to the days of bare knuckle fighting and the underground boxing scene will swell even more.

B N C LITTLEPAGE

H M PERRY

Department of Public Health Medicine,

West Glamorgan Health Authority,

Swansea SA1 5 AQ

Dillner L. Boxing should be counted out, says BMA report. $B M$ 1993;306:1561-2. (12 June.)

2 Drew RH, Templer DI, Schuyler BA. Neuropsychological deficits in active licensed professional boxers. $\mathcal{f}$ Clin Psychol $1986 ; 42: 520-5$

\section{Health promotion in general practice}

\section{Well man clinics won't reduce morbidity}

EDITOR,-Yet again, after 377 patient-hours of hard work, a general practice team concludes that well man clinics fail to reduce cardiovascular risk. The mean body weight, serum total cholesterol concentration, and systolic blood pressure of the men studied rose slightly, though not significantly, and diastolic pressure was unchanged. Nor was there significant improvement in subgroups with a total cholesterol concentration or systolic blood pressure above the authors' thresholds for intervention; the proportion with a diastolic pressure above the threshold was halved, but, because no change in systolic pressure occurred and measurements were not made with a random zero or electronic sphygmomanometer, this is unconvincing.

Weight for height, blood pressure, blood cholesterol concentration, and smoking habit are important to health, and it is difficult to justify ignorance of these simple variables by doctors entrusted with continuing personal care. Beneficial change can be effected by personal care, but this must start from awareness of what initial values are. How this information is obtained, and how it is linked to consequent action, should depend not on judgments by politicians or academics without experience in continuing personal primary care but on what primary care teams have found effective.

In Glyncorrwg colleagues and I used ordinary consultations for ascertainment and used specialised clinics only for follow up. ${ }^{2}$ This policy yielded a much better reduction in risk than any so far reported for well man clinics: the proportion of men aged 20-64 who smoked fell from $61 \%$ in 1968 to $42 \%$ in 1985 , and for men and women whose blood pressure was above the threshold for intervention the mean pressure fell from $186 / 110$ to $146 / 84 \mathrm{~mm} \mathrm{Hg}$. Downward shifts in weight for height and blood cholesterol concentration were much smaller. Like others, ${ }^{3}$ we found reducing the values of these variables even more difficult than controlling smoking or high blood pressure, but still the results of expanded consultations initiated by patients were better than any reported from well person clinics.

Our work was possible only with additional research funding; we had a double workload and half the average general practitioner's net income. The continuing search for ways of developing health promotion as an activity separate from ordinary continuing care reflects tacit acceptance that consultations initiated by patients will never 